\title{
Do Aesthetics Matter in Long-Established Trust?
}

\author{
Zahid Hasan \\ Shanto-Mariam University of \\ Creative Technology \\ Uttara, Dhaka, Bangladesh
}

\author{
Rathindra Chandra Gope \\ Shanto-Mariam University of \\ creative Technology \\ Uttara, Dhaka, Bangladesh
}

\author{
Mohammed Nasir Uddin, \\ $\mathrm{Ph}, \mathrm{D}$ \\ Jagannath University, Dhaka, \\ Bangladesh
}

\begin{abstract}
Recently trust has gained momentum in user experience (UX) research due to the rapid development of e-commerce services, privacy and security issues. It is widely considered that the perception of trust is not only influenced by the website attributes (i.e., usability, functionality), but also by other human factors such as aesthetics. However, it is not clear that which factors of aesthetics influence what dimensions of trust while considering aesthetics and trust as multidimensional constructs. In this paper, insights from an experiment conducted with 30 participants on an e-commerce website was presented. Participants' responses on trust, aesthetics and perceived usability and user satisfaction were collected during the experiment.
\end{abstract}

\section{General Terms}

User Experience, Ecommerce, Human Computer Interaction.

\section{Keywords}

Trust, User Experience, Aesthetics, Usability, User satisfaction.

\section{INTRODUCTION}

As a social being, trust is incorporated into every aspect of human life. At some point in life we have to trust (or distrust) persons, institutions, governments, information, physical things, systems, and more. Its importance spans from individual to social life, from business to technology and even in politics. Without trust social life breaks down, no business transactions take place, new technology is not adopted and even political legitimacy collapses [23]. Researchers do not have a common consensus on what exactly trust is, disagreeing even on basic dimensions. Wang and Emurian [48] identified two main reasons of having multiple dimensions of trust: First, trust is an abstract concept and is often used interchangeably with related concepts such as credibility, reliability, or confidence. Second, trust is a multifaceted subjective concept that incorporates cognitive, emotional, and behavioral dimensions. Moreover, trust has been studied by different disciplines - sociology, psychology, management, marketing, ergonomics, industrial psychology, electronic commerce (e-commerce)- where it has been defined according to specific disciplinary jargon and conceptualized by own understanding and findings. Although no agreement on defining trust is out there, most researchers acknowledge the importance of trust in human life. Regarding the issues mentioned above, trust is also essential when researching in the field of Human-Computer Interaction (HCI). Especially when looking beyond traditional" HCI constructs like usability, trust represents an important factor when interacting with technologies. Minocha and colleagues [33], for example, investigated influencing factors beyond the usability of the website that shape the customer's expectations and experiences. Similarly, Riegelsberger et al. [39] pointed out the importance of trust in HCI. As new technologies are continuously changing the traditional "face to face" buying behavior, designers of such systems now have more responsibilities for supporting trust and trustworthy actions. In the presented experiment we studied trust from an $\mathrm{e}$ commerce perspective since e-commerce systems involve high risk, which is a prerequisite for trust [28]. In this study, "trust in e-commerce" was considered as a multidimensional concept consisting of honesty, benevolence and competence ([11][36][15]). In particular, trust is a relevant component of user experience, supporting a positive experience when interacting with a system. Empirical studies on trust show that there is a clear link between trust and the perception of instrumental qualities of the system (i.e., ease-of-use, performance, privacy and security) (e.g., [11][22][43]). Only a few studies were conducted to investigate the relationship between trust and non-instrumental qualities such as aesthetics (e.g., [12][8][41]). Further, the relation between trust and emotion is still inconclusive and sometimes contradictory ([35][9]). While most of the previous research investigated these relationships by forming trust on some new entities (e.g., fictitious online store), we investigated these relationships with participants already having trust established on e-commerce website.

The paper is organized as follows. First, related work on trust is presented. Second, a detailed description of the conducted experiment is given. Third, the results of our study are introduced and finally, conclusions with indications for further research are discussed.

\section{RELATED WORK}

When designing interactive systems, trust has become a key concern for researchers in HCI. If people do not trust new technology, products or services, along-term usage and adoption is difficult to establish. In this section we discuss the nature of trust and its relevance for HCI.

\subsection{Trust and Trust Concepts}

Trust has been investigated in many different fields. Psychologists, for example, consider trust as an important element for personality development. Philosophers define trust in terms of social values and benefits. In management, trust is related to organizational benefit. It is widely believed that trust can increase business productivity. Researchers from marketing field often define trust within buyer-seller relationship, branding and services (see detailed overview in [48]).

After reviewing the concepts of trust in various disciplines, Wang and Emurian [48] distinguished four common characteristics of trust a) Trustor and trustee (two parties must be involved), b) Vulnerability (uncertainty and risky environment), c) Produced actions (there should be some 
actions as a result of trust relationship ) and d) Subjective matter (perception of trust varies person to person).

In a comprehensive literature work, McKnight and Chervany [29] found that existing trust definitions were based on: a) Types of construct and b) Perceived attributes of trusted party. The three major categories of construct types are: a) Impersonal/Structural trust b) Dispositional trust and c) Personal/Interpersonal trust. Impersonal/Structural trust is the trust that is founded upon social or institutional structures in the situation. It is different than personal attributes, personality trait or state. Dispositional trust is based on the personality attributes of the trusting party, for example one person may have a general tendency to trust others. Personal trust is based on the fact that one person trusts another specific person, persons, or thing(s) in the specific situation. That is, the trusting entity is one person, and trust is directed to another party or parties.

And finally in Interpersonal trust two or more people (or groups) trust each other in the specific situation [29]

\subsection{Trust in E-Commerce}

Trust is considered as one of the most important elements in e-commerce success. People would not purchase products if they find a lack of trust in a business. Trust plays a central role in helping consumers overcome perceptions of risk and insecurity [31]. Honesty, benevolence and competence are the dimensions of trust frequently addressed in online trust literature (e.g., [30][6][39][11][36][15]).

1. Honesty is the belief that another person will keep his or her word, fulfill promises and be sincere.

2. Benevolence is the belief that one of the parties is interested in the wellbeing of the other without intention of opportunistic behavior and motivated by a search for a mutually beneficial relationship.

3. Competence is the degree with which the consumer perceives that the sup- plier is in possession of the necessary knowledge and skills to complete an agreement or exchange.

According to Gefen [15] the specific beliefs of integrity, ability, and benevolence were seen as antecedents to overall trust in e-commerce. Palvia [36] also established the relationship among user trust with belief in the integrity, competence and benevolence of the web vendor. Jarvenpaa et al. [19] reported that there is a correlation between consumer trust and perceived reputation and size of the shop. Moreover, Gefen [14] also pointed out the link between trust and familiarity. According to Cheung and Lee [4] security and privacy control, integrity, competence, third party recognition and legal framework are considered mandatory for trust in Internet shopping, whereas Einwiller [10] focuses on elements such as personal experience, familiarity, affiliation and belonging, transparency, factual signals and heuristic cues as trust enhancing elements. Finally, Bedi and Banati [1] categorized these elements of online trust into five dimensions: appeal of a website (includes design, look and feel and aesthetics), competence of the website, intention of the site, duration of relationship and reputation. The above elaboration already highlights the diversity of how previous research approaches trust in general and trust in e-commerce in particular. In our work, we selected the dimensions of trust, which were also used by Flavian et al. [11], as it enables us to get the three main aspects of trust, which we further relate to constructs such as emotion, aesthetics.

\subsection{Trust and Aesthetics}

Fogg et al. [12] found that instead of paying attention to the rigorous criteria (e.g., privacy policy) when assessing websites regarding trustworthiness, people pay more attention to the superficial aspects of a site, such as visual cues. In a cross-cultural study, Cyr [8] investigated the impact of website design (information design, navigation design, and visual design) on trust level. Their results suggest that perceptions of visual design leading to trust vary by culture. Moreover, Sillence et al. [41] present a framework for understanding trust factors in web based health advice. They found that if the websites are visually unattractive people instantly reject them.

Lindgaard et al. [25] noted that 'visual appeal clearly dominates first impression judgments of other characteristics such as perceived usability and trustworthiness. Judgments about credibility of websites were found less consistency but noteworthy between extremely short and long exposure [37]. From their experiment aesthetics were moderately correlated with credibility in both phases $(r=.580$ and $r=.484)$. Karvonen [21] also discusses the importance of beauty in creating the feeling of online trust.

Most of the researches that explicitly focused on trust and aesthetics relationship investigated the perception of trust at the initial judgment by exposing the stimuli which were not familiar to the participants (see e.g., [37][25][41]). Those experiments broaden our knowledge regarding how (fast) trust is formed during our first impression as Lindgaard et al. [25] showed that people are able to judge the visual appeal, trust and usability of websites consistently upon viewing them only for $50 \mathrm{msec}$. Additionally, Papachristos and Avouris [37] showed how consistent these judgments are over time (after viewing $500 \mathrm{msec}$ in the first phase and no time limit in the second phase). The above mentioned work shows already the relevant connection of visual aesthetics and trust. However, there are still a lot of issues open concerning the investigation of aesthetics and trust. For example, we found no work investigating the influence of aesthetics on long-established trust. Thus, we decided to address this issue in our experiment.

\section{THE STUDY}

Inspired by the previous work on trust and the lack of research on the relationship between trust and non-instrumental aspects, we set up an experimental study. We selected ebay.com (http://www.ebay.com/) as e-commerce case example and used two versions of the same website (attractive versus unattractive) with 30 participants. The goal of the study was to manipulate the visual aesthetics of the website while keeping the other variables fixed with a view to compare the influence of aesthetics on trust, as well as on usability and user satisfaction.

Overall we wanted to contribute to a better understanding on trust as element of user experience and its relationship with other human factors (i.e., aesthetics). In order to achieve these goals we formulated the following hypothesis:

H: The degree of aesthetics perceived by the user has a positive influence on the degree of trust.

\subsection{Participants}

In total, 30 (16 male, 14 female) under-graduate students took part in the experiment on voluntarily basis. We had to exclude 3 male participant from the analysis due to procedural concerns. The participants' age ranged from 20 to 26 years $(\mathrm{M}=22.5, \mathrm{SD}=5.66)$. All of them were students of a local 
University from different disciplines. None of them had previous experience on buying products from ebay.com, however ebay was familiar to all of them and none of the participants had seen the mobile version of the ebay.com website before.

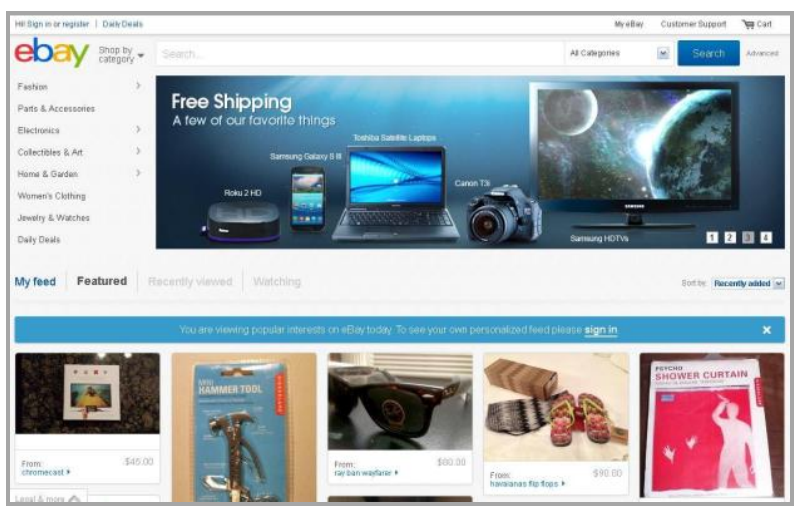

Figure. 1a. The main version of ebay.com.

\begin{tabular}{|l|}
\hline Browse Categories \\
\hline Popular Categories \\
Motors \\
Clothing, Shoes \& Accessories \\
Sporting Goods \\
Jewelry \& Watches \\
\hline \multicolumn{2}{|c|}{ Sign in } \\
\hline
\end{tabular}

Figure. 1b. The mobile version of ebay.com.

\subsection{Measured variables}

The following variables were further investigated within the experiment. A combination of several questionnaires and instruments was used to measure the different variables.

1. Trust. Trust was measured using the "scale for measuring website user trust" developed by Flavian et al. [11]. Thus, the three different dimensions of trust, namely honesty, benevolence and competence are measured (see detailed description of each level in the related work section).

2. Aesthetics. Aesthetics was measured using the VisAwi (Visual Aesthetics of Website Inventory) scale [34]. It is a new tool to measure perceived website aesthetics. This questionnaire is based on four interrelated facets of perceived visual aesthetics of websites: simplicity, diversity, colorfulness, and craftsmanship (see previous description of the pre-study).

3. Usability. We additionally investigated usability, as it is still relevant for the overall UX, as well as to explore any effects of aesthetics on the perceived usability. Usability was measured by means of 4 items: easy to use, easy navigation, convenient use, easy orientation based on the "scale for measuring perceived website usability" by Lavie and Tractinsky [24].
4. User satisfaction. Finally, four items were included in the questionnaire measuring the website user satisfaction based on the questionnaire developed by Flavian et al. [11].

\subsection{Procedure}

The participants were invited to the usability laboratory. Upon arrival, each of them were briefed about the generic purpose of the study and asked to sign a consent form. A demographic form was also provided.

Two versions of ebay.com websites were used (see Figure 1a and $1 \mathrm{~b}$ ). One of the websites (high attractive) was the main version and another one (less attractive) was the mobile version. In order to validate our assumption that the main website of ebay.com was more attractive than the mobile version, we conducted a pre-study for assessing the visual attractiveness of those two websites. Aesthetics were measured using the VisAwi (Visual Aesthetics of Website Inventory) scale developed by Moshagen and Thielsch [34]. The VisAwi scale includes four facets of visual attractiveness of websites: simplicity, diversity, colorfulness, and craftsmanship. Simplicity refers to the classical aesthetics dimension including clarity, orderliness, homogeneity, grouping, and balance, whereas the diversity is related to the expressive aesthetic dimensions reflecting visual richness, dynamics, variety, creativity, and novelty. The colorfulness facet reflects the evaluation of individual color and their composition. Finally, craftsmanship reflects whether the site was designed with skill and care using modern technologies. The first two facets are measured by five items and the last two facets are measured by four items. This instrument was pilot-tested with 15 bachelor students at the same university from different background.

A paired-sample t-test revealed that average aesthetics of the main website was significantly higher than that of the mobile website $(t(14)=2.40, p=.043)$. Regarding each dimension of aesthetics, colorfulness and craftsmanship were significantly higher for the main website $(\mathrm{t}(14)=2.58, \mathrm{p}=.032$ and $t(14)=5.398, p=.000$ respectively), diversity was approaching higher for the main website $(t(14)=2.20, p=.055)$, however the differences in simplicity were not significant. In sum, the attractiveness of the main version of the website was perceived higher than the mobile version. This result confirmed our assumptions on the aesthetics of the two websites we wanted to investigate in our experiment.

Participants were asked to perform some simple tasks (finding and buying a book) on both versions (attractive and unattractive) of ebay website. In order to minimize the learning effect, the task order was also balanced across participants. After finishing the tasks users were asked again to fill in the questionnaires addressing trust, aesthetics, usability, user satisfaction.

\section{RESULTS}

In the following sections the main findings from our experiment are reported, highlighting the influences between the measured variables. Participants were asked to perform a simple task. This task consisted of finding and buying (until the payment) a specific book of either paperback or hardcover on both websites. We choose this simple task so that there should not be any actual usability issues on both websites and this type of buying a book from online was employed as a part of experimental tasks in [19]. Within this section, we report relevant insights on trust in relation to emotion and aesthetics after the interaction with the websites. 


\subsection{Analysis of Trust Dimensions}

A paired-samples t-test was conducted to compare the ratings of the three constructs of trust (honesty, benevolence, competence) in the high-aesthetics (main website) and lowaesthetics conditions (mobile website). There was a significant difference in the scores for honesty $(\mathrm{t}(28)=3.12, \mathrm{p}$ $=.004)$, for benevolence $(\mathrm{t}(28)=3.01, \mathrm{p}=.005)$, and for competence $(\mathrm{t}(28)=3.99, \mathrm{p}=.000)$. Similar results were found in post-usage case from the analysis of $2 * 2$ ANOVA for honesty $(\mathrm{F}(1,28)=7.654, \mathrm{p}=.010)$, for benevolence $(\mathrm{F}(1,28)=6.233, \mathrm{p}=.019)$ and for competence $(\mathrm{F}(1,28)=$ $12.021, \mathrm{p}=.002)$. These results show that trust is affected by aesthetics on all three levels (honesty, benevolence, competence).

\subsection{Canonical Correlation Analysis (CCA)}

In order to understand which attributes of aesthetics contribute to the experience of trust with respect to competence, benevolence and honesty, canonical correlation analysis was performed. CCA is most appropriate when a researcher desires to examine the relationship between two variable sets [42]. It identifies components of one set of variables that are most highly related linearly to the components of the other set of variables. One set may be viewed as the predictor variables while the other set may be considered the criterion or outcome variable. Because the measured variables utilized for the predictor or criterion variables may represent different dimensions, more than one linear combination may emerge [18]. We used canonical correlation analysis for each of four cases (positive affect main website, positive affect mobile website, negative affect main website and negative affect mobile website). Among them only positive affect main website was statistically significant.

Tests of dimensionality for the canonical correlation analysis, as shown in Table 4, indicate that the first of the three canonical dimensions was statistically significant at the .05 level (Wilks's lambda=.229 and p=.000). Dimension 1 had a canonical correlation of 0.811 between the two sets of variables which explains 52.77 percent variance in the dependent variable.

Table 1. Tests of Canonical Dimensions.

\begin{tabular}{l|l|l|l|l|l}
\hline Dimensions & \multicolumn{1}{c}{ Correlation } & \multicolumn{1}{c}{ Hyp.df } & Err.df & Sig. \\
\hline 1 & 0.81 & 38 & 12 & 61.14 & .00 \\
\hline 2 & 0.53 & 1.78 & 6 & 48 & .01 \\
\hline 3 & 0.27 & 0.99 & 2 & 25 & .03 \\
\hline
\end{tabular}

Dimension1 refers to the first linear correlation between aesthetics and trust variables and so on.

The structure correlations, which show how the original trust variables (competence, benevolence and honesty) and aesthetics variables (simplicity, diversity, color, craftsmanship) load on canonical variable trust and aesthetics respectively are shown in table 5 and figure 5.

Table 2. Factor loadings on dimension 1.

\begin{tabular}{l|l|l|l}
\hline Trust Var. & \multicolumn{1}{l}{ Dimension1 } & Aesthetics var. & Dimension1 \\
\hline Competence & 0.88 & Craftsmanship & 0.81 \\
\hline Honesty & 0.95 & Diversity & 0.51 \\
\hline Benevolence & \multirow{2}{*}{0.86} & Simplicity & 0.89 \\
\cline { 3 - 4 } & & Color & 0.74 \\
\hline
\end{tabular}

Dimension1 refers to the first linear correlation between aesthetics and trust variables.

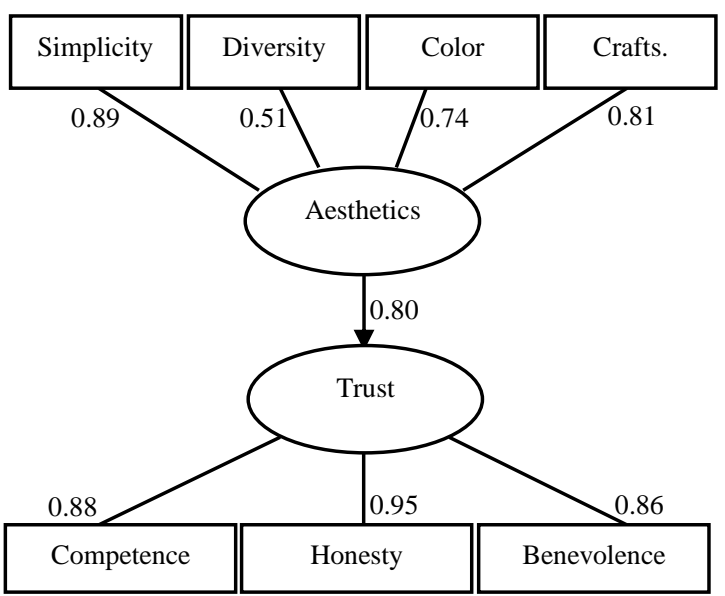

Fig. 2. Canonical relationships between two sets of variables.

Multivariate Multiple Regression Analysis (MMR) was performed on trust (competence, honesty, benevolence) as depended variables and aesthetics (craftsmanship, color, diversity, simplicity) as independent variables. Multivariate test revealed that only craftsmanship was a significant predictor for overall trust $(\mathrm{F}=3.438, \mathrm{p}=0.034)$. In univariate test, when honesty was predicted it was found that simplicity $($ Beta $=0.404, p=0.026)$ and color $($ Beta $=0.394, p=.026)$ were significant predictors. Craftsmanship was found to be good predictor for competence $($ Beta $=0.253, \mathrm{p}=.001)$ while benevolence was predicted by simplicity (Beta $=0.468, \mathrm{p}=$ $.023)$.

Table 3. Tests of Multivariate Regression on four dimensions of trust as dependent variables and four dimensions of aesthetics as independent variables.

\begin{tabular}{l|l|l|l|l}
\hline Dependent Var. & Independent Var. & Beta & t-value & Sig. \\
\hline Competence & Craftsmanship & 0.25 & 2.74 & 0.11 \\
\hline Honesty & Simplicity & 0.40 & 2.35 & 0.02 \\
\hline Honesty & Color & 0.39 & 2.59 & 0.01 \\
\hline Benevolence & Simplicity & 0.47 & 2.42 & 0.02 \\
\hline
\end{tabular}

\section{DISCUSSION}

In order to investigate the influence of aesthetics on trust in an experimental setting, we used two different versions of the ebay.com website - a higher and a lower attractive version, referring to the main and mobile version of the website.

Regarding the individual dimensions of aesthetics (simplicity, diversity, color, craftsmanship) and individual dimensions of trust (competence, benevolence and honesty), competence is predicted by craftsmanship, honesty is predicted by both simplicity and color while benevolence is predicted by simplicity. As stated earlier, craftsmanship reflects whether the site was designed with skill and care using modern technologies. In order to make the users feel that the company is competent enough to fulfill their needs, designer are advised to focus on careful consideration of craftsmanship of website, that is the website needs to be harmoniously designed and the design ideas have to be skilfully integrated

[34]. [34] characterized craftsmanship as the skillful and coherent integration of all relevant design dimensions. Another aspect of craftsmanship is modernism, which means whether the website is up to date. The more users feel the website is trendy and modern using state of the art 
technology, the more they are likely to put trust on that. So it is highly recommended that newer technologies should be incorporated in website design. While integrating modern technologies and professional design patterns, designers should also focus on simplicity of the appearance as it boosts the impression of both honesty and benevolence. Simplicity, similar to classical aesthetics proposed by [24] reflects the aspects that facilitate perception and the processing of a layout, such as clarity, orderliness, homogeneity, grouping, and balance [34]. Finally color seems to influence the perception of honesty as well. This observation can be explained by the findings of [7], where color was found to have impact on classical aesthetics. So, the variable classical aesthetics or simplicity might act as mediator variable in color-honesty relationship.

\section{CONCLUSION}

This study addresses an important aspect of HCI research: It shows how trust is related to different user experience components such as perception of aesthetics. This in turn is especially interesting for designers, as such relationships point out the potential design space. We could also identify the individual contribution of aesthetic dimensions on individual dimensions of trust. These findings will be helpful for designers when the websites need to be redesigned, for example, if the website is found not to be trustworthy in a specific dimension, i.e. benevolence. In this case, the designers might consider to redesign the page layout only in order to improve simplicity rather than changing the other dimensions of aesthetics - which will also save time and effort as well

The biggest drawback of this study is the small number of participants and for this it was not possible to use structural equation analysis (SEM) as it typically requires large sample sizes. Using SEM would be well justified in our case as it provides a more accurate representation of the latent variables than Canonical Correlation Analysis (CCA) does[18] and also provides greater flexibility to test the structure coefficients [3].

For future work, we plan to extend our experiment towards more participants in order to examine the influences of emotion and personality on trust. Moreover, further experiments with diverse user groups should be conducted to gather additional insights on how user characteristics influence the level of trust. Furthermore, we want to investigate if the used type of device and underlying technology also have an influence on the perceived trust. For example, we want to compare smaller and bigger screens (mobile/tablet versus LED screens) in order to look for differences in trust. Finally, we intend to further explore the emotion induction procedure, so that the intended emotional state is prolonged over the interaction time, and does not disappear immediately. Thus, better contextualization of the experiment is needed.

\section{REFERENCES}

[1] Bedi, P., and Banati, H. Assessing user trust to improve web usability. Journal of Computer Science 2, 3 (2006), 283-7.

[2] Bradley, M., and Lang, P. Measuring emotion: the selfassessment manikin and the semantic differential. Journal of behavior therapy and experimental psychiatry 25,1 (1994), 49-59.

[3] Fan, X. Canonical correlation analysis and structural equation modeling: What do they have in common?
Structural Equation Modeling: A Multidisciplinary Journal, 4 (1997), 65-79.

[4] Cheung, C., and Lee, M. Trust in internet shopping: A proposed model and measurement instrument. AMCIS 2000 Proceedings (2000), 406.

[5] Converse, B., Lin, S., Keysar, B., and Epley, N. In the mood to get over yourself: Mood affects theory-of-mind use. Emotion 8, 5 (2008), 725

[6] Corritore, C., Kracher, B., and Wiedenbeck, S. On-line trust: concepts, evolving themes, a model. International Journal of Human-Computer Studies 58, 6 (2003), 737 758.

[7] Coursaris, C.K. and Sweirenga, S.J. and Watrall, E. An empirical investigation of color temperature and gender effects on web aesthetics. Journal of Usability Studies 58, 3 (2003), 103117.

[8] Cyr, D. Modeling web site design across cultures: Relationships to trust, satisfaction, and e-loyalty. Journal of Management Information Systems 24, 4 (2008).

[9] Dunn, J., and Schweitzer, M. Feeling and believing: the influence of emotion on trust. Journal of Personality and Social Psychology 88, 5 (2005), 736.

[10] Einwiller, S., Geissler, U., and Will, M. Engendering trust in internet business using elements of corporate branding. AMCIS 2000 Proceedings (2000), 54.

[11] Flavian, C., Guinaliu, M., and Gurrea, R. The role played by perceived usability, satisfaction and consumer trust on website loyalty. Information \& Management 43, 1 (2006), 1-14.

[12] Fogg, B., Soohoo, C., Danielson, D., Marable, L., Stanford, J., and Tauber, E. How do people evaluate a web sites credibility. Citeseer (2002).

[13] Gambetta, D. Can we trust trust. Trust: Making and Breaking Cooperative Rela- tions, Department of Sociology, University of Oxford (2000), 213\{237.

[14] Gefen, D. E-commerce: the role of familiarity and trust. Omega 28, 6 (2000).

[15] Gefen, D. Reections on the dimensions of trust and trustworthiness among online consumers. ACM SIGMIS Database 33, 3 (2002), 38\{53.

[16] Gross, J., and Levenson, R. Emotion elicitation using films. Cognition \& Emotion 9, 1 (1995), 87-108.

[17] Huang, J., and Fox, M. An ontology of trust: formal semantics and transitivity. In Proceedings of the 8th international conference on Electronic commerce, ACM (2006), 259-270.

[18] Guarino, AJ A comparison of first and second generation multivariate analyses: Canonical correlation analysis and structural equation modeling. In Florida Journal of Educational Research, (2004), 259\{270.

[19] Jarvenpaa, S., Tractinsky, N., and Saarinen, L. Consumer trust in an internet store: A cross-cultural validation. Journal of Computer-Mediated Communication 5, 2 (1999). 
[20] Jones, G., and George, J. The experience and evolution of trust: Implications for cooperation and teamwork. Academy of management review (1998), 531-546.

[21] Karvonen, K. The beauty of simplicity. In Proceedings on the 2000 conference on Universal Usability, ACM (2000), 85-90.

[22] Khasawneh, M., Bowling, S., Jiang, X., Gramopadhye, A., and Melloy, B. A model for predicting human trust in automated systems. Origins (2003).

[23] Kosfeld, M., Heinrichs, M., Zak, P., Fischbacher, U., and Fehr, E. Oxytocin in- creases trust in humans. Nature 435, 7042 (2005), $673\{676$.

[24] Lavie, T., and Tractinsky, N. Assessing dimensions of perceived visual aesthetics of web sites* 1 . International Journal of Human-Computer Studies 60, 3 (2004), 269298.

[25] Lindgaard, G., Dudek, C., Sen, D., Sumegi, L., and Noonan, P. An exploration of relations between visual appeal, trustworthiness and perceived usability of homepages. ACM Transactions on Computer-Human Interaction (TOCHI) 18, 1 (2011).

[26] Lumsden, J., and MacKay, L. How does personality affect trust in b2c e-commerce? In Proceedings of the 8th International Conference on Electronic Commerce (ICEC'2006) (2006).

[27] Macht, M., Roth, S., and Ellgring, H. Chocolate eating in healthy men during experimentally induced sadness and joy. Appetite 39, 2 (2002), 147\{158.

[28] Mayer, R., Davis, J., and Schoorman, F. An integrative model of organizational trust. Academy of management review (1995), 709-734

[29] McKnight, D., and Chervany, N. The meanings of trust. Citeseer (1996).

[30] McKnight, D., and Chervany, N. What is trust? a conceptual analysis and an interdisciplinary model. AMCIS 2000 Proceedings (2000), 382.

[31] McKnight, D., Choudhury, V., and Kacmar, C. Developing and validating trust measures for ecommerce: An integrative typology. Information systems research 13, 3 (2003), 334-359.

[32] Mehrabian, A. Basic dimensions for a general psychological theory. Cambridge, MA: Oelgeschlager, Gunn \& Hain (1980).

[33] Minocha, S., Petre, M., Tzanidou, E., Van Dijk, G., Roberts, D., Gassman, N., Millard, N., Day, B., and Travis, D. Evaluating e-commerce environments: approaches to cross-disciplinary investigation. In CHI'06 extended abstracts on Human factors in computing systems, ACM (2006), 1121-1126.

[34] Moshagen, M., and Thielsch, M. Facets of visual aesthetics. International Journal of Human-Computer Studies 68, 10 (2010), 689-709.

[35] Neerincx, M., and Streefkerk, J. Interacting in desktop and mobile context: Emotion, trust, and task performance. Ambient Intelligence (2003), 119-132.

[36] Palvia, P. The role of trust in e-commerce relational exchange: A unified model. Information \& Management 46, 4 (2009), 213-220.
[37] Papachristos, E., and Avouris, N. Are first impressions about websites only related to visual appeal? HumanComputer Interaction-INTERACT 2011 (2011).

[38] Rammstedt, B., and John, O. Measuring personality in one minute or less: A 10-item short version of the big five inventory in English and German. Journal of Research in Personality 41, 1 (2007), $203\{212$.

[39] 39. Riegelsberger, J., Sasse, M., and McCarthy, J. The mechanics of trust: A framework for research and design. International Journal of Human-Computer Studies 62, 3 (2005), 381- 422 .

[40] Schoorman, F., Mayer, R., and Davis, J. An integrative model of organizational trust: Past, present, and future. The Academy of Management Review ARCHIVE 32, 2 (2007), 344-354.

[41] Sillence, E., Briggs, P., Harris, P., and Fishwick, L. A framework for understanding trust factors in web-based health advice. International Journal of Human-Computer Studies 64, 8 (2006), 697-713.

[42] Sherry, A. and Henson, R.K., Conducting and interpreting canonical correlation analysis in personality research: A user-friendly primer. Journal of Personality Assessment. (2005)

[43] Suh, B., and Han, I. The impact of customer trust and perception of security control on the acceptance of electronic commerce. International Journal of Electronic Commerce 7, 3 (2003), 135-161.

[44] Sutclife, A., and De Angeli, A. Assessing interaction styles in web user interfaces. Human-Computer Interaction-INTERACT 2005 (2005), 405\{417.

[45] Sutherland, P., and Tan, F. The nature of consumer trust in b2c electronic commerce: A multi-dimensional conceptualization. In Proceedings of the International Conference of the Information Resources Management Association (2004), 23\{26.

[46] Tractinsky, N. Aesthetics and apparent usability: empirically assessing cultural and methodological issues. In Proceedings of the SIGCHI conference on Human factors in computing systems, ACM (1997), 115-122.

[47] Tractinsky, N., Katz, A., and Ikar, D. What is beautiful is usable. Interacting with computers 13, 2 (2000), 127-145.

[48] Wang, Y., and Emurian, H. An overview of online trust: Concepts, elements, and implications. Computers in Human Behavior 21, 1 (2005), 105-125.

[49] Watson, D., Clark, L., and Tellegen, A. Development and validation of brief measures of positive and negative affect: The panas scales. Journal of personality and social psychology 54, 6 (1988), 1063.

[50] Westermann, R., Spies, K., Stahl, G., and Hesse, F. Relative effectiveness and validity of mood induction procedures: a meta-analysis. European Journal of Social Psychology 26, 4 (1996), 557-580.

[51] Williams, M. In whom we trust: Group membership as an affective context for trust development. Academy of Management Review (2001), 377-396. 